\title{
Electrospun fibres from polyvinyl alcohol, poly(styrene sulphonic acid-co-maleic acid), and imidazole for proton exchange membranes
}

\author{
Romklaw Boonpoo-nga ${ }^{\mathrm{a}}$, Manus Sriring ${ }^{\mathrm{a}}$, Pitak Nasomjai ${ }^{\mathrm{a}}$, Surangkhana Martwiset ${ }^{\mathrm{b}, \mathrm{c}, *}$ \\ ${ }^{a}$ Department of Chemistry, Faculty of Science, Khon Kaen University, Khon Kaen 40002 Thailand \\ b Materials Chemistry Research Centre, Department of Chemistry and Centre of Excellence for \\ Innovation in Chemistry, Faculty of Science, Khon Kaen University, Khon Kaen 40002 Thailand \\ ${ }^{c}$ Nanotec-KKU Centre of Excellence on Advanced Nanomaterials for Energy Production and Storage, \\ Khon Kaen 40002 Thailand
}

${ }^{*}$ Corresponding author, e-mail: surama@kku.ac.th

Received 18 Dec 2013

Accepted 5 May 2014

\begin{abstract}
Electrospun fibres from polyvinyl alcohol (PVA), poly(styrene sulphonic acid-co-maleic acid) (PSSA-MA), and imidazole for potential use as proton conducting membranes at elevated temperatures were prepared and characterized. The effect of PSSA-MA content $(9,17,25,33,42$, and $50 \%$ by weight of PVA) on solution properties was investigated. Fibre mats were obtained from solutions with 9-33\% PSSA-MA. Solution viscosity increased with increasing PSSA-MA until reaching a maximum at 33\% PSSA-MA. The effect of PSSA-MA content on fibre size and morphology was studied using scanning electron microscopy. Fibre diameter was found to increase with increasing solution viscosity. A solution with $25 \%$ PSSA-MA provided uniform and bead-free fibres with an average diameter of $485 \mathrm{~nm}$. Thermal crosslinking of electrospun fibres was confirmed by attenuated total reflection Fourier transform infrared spectroscopy and thermogravimetric analysis. Electrospun fibres were thermally stable up to $250^{\circ} \mathrm{C}$. Fibres containing $25 \%$ PSSA-MA had a proton conductivity in nonhumidified conditions comparable to that of a solvent-cast membrane with the same composition. The proton conductivity of a solvent-cast membrane was slightly higher than that of fibres over the temperature range studied.
\end{abstract}

KEYWORDS: conducting polymers, electrospinning, fuel cells, polyelectrolytes

\section{INTRODUCTION}

During the last decade, as a result of the decrease of fossil fuels and the increase of emission of greenhouse gases, many investigations for alternative environmental friendly fuel and energy sources have been conducted. Promising energy sources for vehicle and portable electronic devices are polymer electrolyte membrane fuel cells (PEMFCs) and direct methanol fuel cells (DMFCs). Among acid polymers serving as electrolytes in PEMFCs and DMFCs, Nafion, a perfluorosulphonated membrane with a fluorocarbon backbone and sulphonic acid pendants, is the most commercially successful membrane. Its use, however, is limited by high cost, high methanol permeability, and a decrease in proton conductivity at high temperatures and low humidity ${ }^{1-3}$.

Reduction of methanol crossover through polymer electrolyte membranes (PEMs) can be achieved by either rational selection of membrane materials or manipulation of membrane morphology $y^{4,5}$. In the field of membrane pervaporation for dehydra- tion of alcohols, many hydrophilic polymers such as polyvinyl alcohol (PVA) have been used because they preferentially permeate water and retain alcohol ${ }^{6,7}$. Although high water uptake facilitates proton conduction, an excessive water swelling leads to low mechanical strength in PEMs. To overcome the swelling problem in PVA-based membranes, the membranes are either crosslinked or incorporated with inorganic materials $^{8-10}$.

The development and the commercialization of perfluorosulphonic acid membranes are limited to operating temperatures below $100{ }^{\circ} \mathrm{C}$ because the proton transport mechanism, namely vehicular mechanism, relies on the presence of water ${ }^{11,12}$. Operation at higher temperatures offers many advantages including the increase in fuel cell efficiency ${ }^{13}$, decrease in required platinum catalyst loading ${ }^{14}$, improvement in CO tolerance ${ }^{15}$, and simpler heat management. Amphoteric nitrogen-based heterocycles, such as imidazole, pyrazole, and benzimidazole, were shown to have intrinsic conductivity ${ }^{16,17}$. The use of these heterocycles as proton solvents provided comparable proton 
conductivities to that of hydrated polymers ${ }^{18,19}$.

Electrospinning is a simple method to produce fibrous materials with diameters ranging from nanometres to micrometres. In recent report, Tamura and Kawakami demonstrated that upon an introduction of nanofibres, membrane stability was improved, and gas permeability can be controlled ${ }^{20}$. Electrospinning of Nafion solution was challenging due to aggregation of ionic groups ${ }^{21}$; however, with an addition of PVA, sprayable solutions were produced ${ }^{22}$. Our group also reported the successful preparation of electrospun fibres of poly(styrene sulphonic acid) (PSSA) and PVA. The water stability of the fibres was improved by heat-treatment at $120^{\circ} \mathrm{C}^{23}$.

In this work, electrospun fibres of PVA, poly(styrene sulphonic acid-co-maleic acid) (PSSA-MA), and imidazole were prepared and characterized. PSSA-MA was chosen as proton source because of its low cost and relative high proton conductivity. PVA would enhance the spinnability of PSSA-MA into fibres, and provide hydrophilic properties, high density of hydroxyl groups for crosslinking reaction and excellent methanol barrier. Imidazole was employed as proton solvent. The effect of PSSA-MA content on solution properties, shape, and size of the fibres was studied. Surface morphology was characterized using scanning electron microscopy. Thermal properties of fibres were also investigated. Proton conductivity of fibres was measured using impedance spectroscopy in non-humidified condition, and the result was compared with that of solvent-cast membrane with the same PSSA-MA content.

\section{MATERIALS AND METHODS}

\section{Materials}

Poly (vinyl alcohol) (PVA, 95\% hydrolysed, average MW 95 000) was purchased from Acros Organics. Poly(4-styrenesulphonic acid-co-maleic acid) (PSSA-MA, SSA:MA = 3:1, MW 20000 ), and imidazole $(99 \%)$ were purchased from Sigma-Aldrich. All chemicals were used as received.

\section{Characterization}

Surface morphology was studied using a scanning electron microscope (LEO 1450VP, UK). The average diameter of the fibres was determined by analysing 200 fibres in micrograph using WCIF ImageJ program. The viscosities of polymer solutions were measured at room temperature at a speed of $20 \mathrm{rpm}$ using a digital viscometer (Brookfield, model DV-II). The reported values were the means of three measurements. Fourier transform infrared (FTIR) spec-

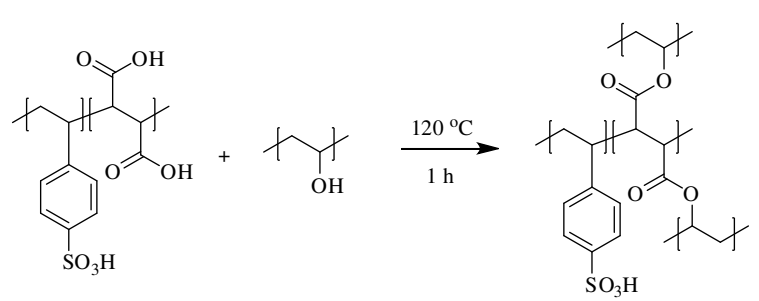

Fig. 1 Crosslinking reaction between PSSA-MA and PVA.

tra were measured on a Bruker FTIR spectrometer (Tensor 27) with Opus 7.0 measuring in the range of $4000-450 \mathrm{~cm}^{-1}$. Thermogravimetric-differential thermal analysis (TGA-DTA) was carried out using Pyris Diamond TGA/DTA (PerkinElmer) system with a heating rate of $10^{\circ} \mathrm{C} / \mathrm{min}$ from $35-700^{\circ} \mathrm{C}$ under nitrogen atmosphere. Glass transition temperature $\left(T_{\mathrm{g}}\right)$, melting temperature $\left(T_{\mathrm{m}}\right)$ and crystallization temperature $\left(T_{\mathrm{c}}\right)$ were obtained by differential scanning calorimetry (DSC) using a PerkinElmer Pyris 1 DSC. Samples were analysed with a heating rate of $10^{\circ} \mathrm{C} / \mathrm{min}$ from $50-250^{\circ} \mathrm{C}$ under nitrogen flow.

\section{Fibre preparation by electrospinning}

Desired amounts of PSSA-MA, 9, 17, 25, 33, 42, and $50 \%$ by weight of PVA, were added to a $10 \mathrm{wt} \%$ aqueous PVA solution. Imidazole was then added to the solution. The amount of imidazole used was fixed at $44 \%$ by weight of PSSA-MA to isolate the doping effect. The solutions were stirred overnight to ensure adequate mixing before electrospinning process prior to loading into a plastic syringe equipped with a 22-gauge stainless steel needle, connected to a highvoltage supply (DEL High-Voltage (0-100 kV), DEL Electronics Corp.). The polymer solutions were spun at a flow rate of $0.5 \mathrm{ml} / \mathrm{h}$ using a syringe pump (TERUMO Terufusion syringe pump TE-331, Japan). A piece of flat aluminium foil was placed $20 \mathrm{~cm}$ below the tip of the needle. The positive voltage applied was $19.4 \mathrm{kV}$. All experiments were performed at room temperature. The obtained fibres were later heated on a glass plate at $120^{\circ} \mathrm{C}$ for $1 \mathrm{~h}$ to induce crosslinking reaction (Fig. 1) ${ }^{24}$.

\section{Membrane preparation}

PSSA-MA (25\% by weight of PVA) and imidazole (44\% by weight of PSSA-MA) were added to a 10 wt.\% PVA solution. The solution was stirred for 20 min prior to casting on a plastic plate, and drying at $80^{\circ} \mathrm{C}$ for $18 \mathrm{~h}$. The dried membrane was peeled off, and then heated on a glass plate at $120^{\circ} \mathrm{C}$ for $1 \mathrm{~h}$ to induce crosslinking reaction. 
Table 1 Electrospinning of PVA/PSSA-MA/imidazole solutions.

\begin{tabular}{ll}
\hline PSSA-MA content (wt.\%) & Observations \\
\hline 9 & Fibre mat \\
17 & Fibre mat \\
25 & Fibre mat \\
33 & Fibre mat \\
42 & Solution droplets \\
50 & Solution droplets \\
\hline
\end{tabular}

\section{Proton conductivity}

Proton conductivity measurements were made using impedance spectroscopy (Agilent E4980A Precision LCR Meter). The goal-coated membranes were placed between two electrodes followed by an application of $500 \mathrm{mV}$ excitation voltage with a logarithmic frequency sweep from $1 \times 10^{2} \mathrm{~Hz}$ to $1 \times 10^{6} \mathrm{~Hz}$. All measurements were conducted from $120-200^{\circ} \mathrm{C}$ at $40{ }^{\circ} \mathrm{C}$ intervals. Resistance values were taken at the minimum imaginary response in a $Z^{\prime}$ versus $Z^{\prime \prime}$ plot to determine conductivity. The membrane conductivity was calculated from the membrane resistance, $R$, using $\sigma=l / R A$, where $\sigma$ is the proton conductivity, $l$ is the membrane thickness, and $A$ is the crosssectional area of the membrane sample.

\section{RESULTS AND DISCUSSION}

\section{Electrospinning of polymer solutions}

Electrospinning of solutions of PVA, PSSA-MA, and imidazole with various PSSA-MA contents, that is, $9,17,25,33,42$, and $50 \%$, was conducted at room temperature and constant electrospinning conditions (19.4 kV, $0.5 \mathrm{ml} / \mathrm{h}, 20 \mathrm{~cm}$ tip-to-target distance). Fibre mats were obtained from solutions with 9, 17, 25, and $33 \%$ PSSA-MA, while solution droplets were observed at higher PSSA-MA concentrations (Table 1). Solution properties play important roles in the synthesis of fibre via electrospinning. Fibre formation depends highly on viscosity, charge density, and surface tension ${ }^{25-27}$. Solution viscosities were plotted against PSSA-MA content (Fig. 2). It was found that solution viscosities increased with increasing PSSA-MA up to $33 \%$. A drastic drop in viscosity at higher PSSA-MA concentrations, resulting from phase separation, is likely responsible for the non-spinnability of polymer solutions with 42 and 50\% PSSA-MA.

SEM images of filers with 9-33\% PSSA-MA show the increase in fibre size with increasing PSSA-MA (Fig. 3). The high viscosity results in a larger polymer jet and a consequent deposition of fibres with a larger diameter ${ }^{28}$. Only solution with

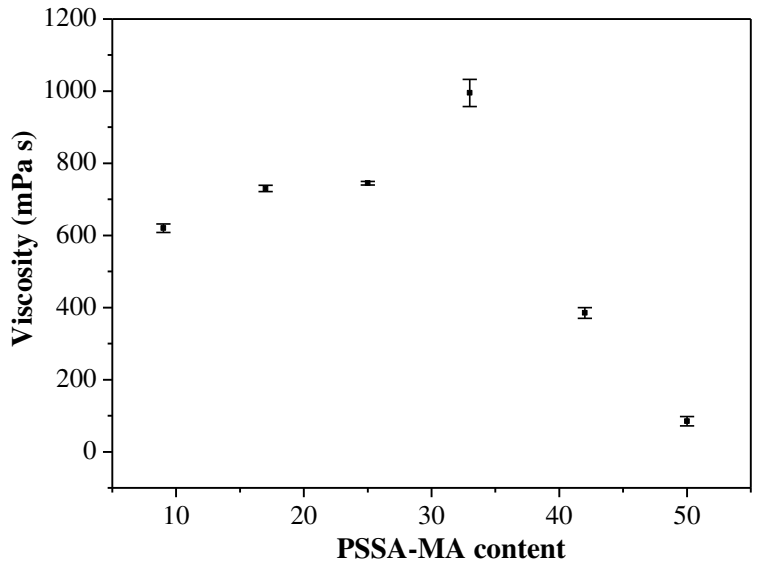

Fig. 2 Viscosities of polymer solutions as a function of PSSA-MA content.
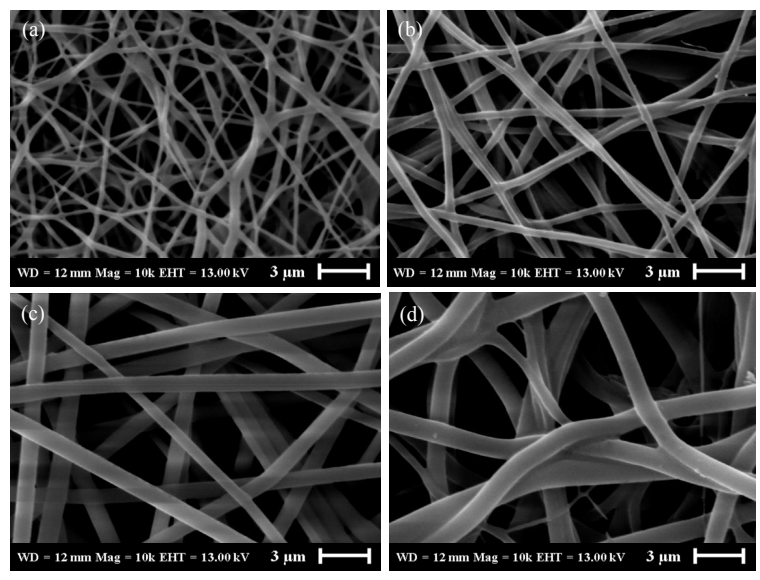

Fig. 3 SEM images (10 000 $\times$ magnification) of electrospun fibres with various PSSA-MA contents. (a) 9, (b) 17, (c) 25, and (d) $33 \%$.

25\% PSSA-MA provided uniform and untangled fibres with an average diameter of $485 \pm 39 \mathrm{~nm}$ (Fig. 4). The thickness of the fibre mat was $0.32 \mathrm{~mm}$.

\section{Membrane preparation}

Proton conducting membrane containing $25 \%$ PSSA-MA was prepared from casting aqueous solution of PVA, PSSA-MA and imidazole on a plate. The membrane was allowed to dry at $80^{\circ} \mathrm{C}$ prior to crosslinking reaction at $120^{\circ} \mathrm{C}$ for $1 \mathrm{~h}$. Free standing membrane with a thickness of $0.41 \mathrm{~mm}$ was obtained.

\section{Fibre and membrane compositions}

ATR-FTIR spectra of fibres comprising PVA, PSSA-MA and imidazole with four PSSA-MA concentrations after heat treatment were shown in 


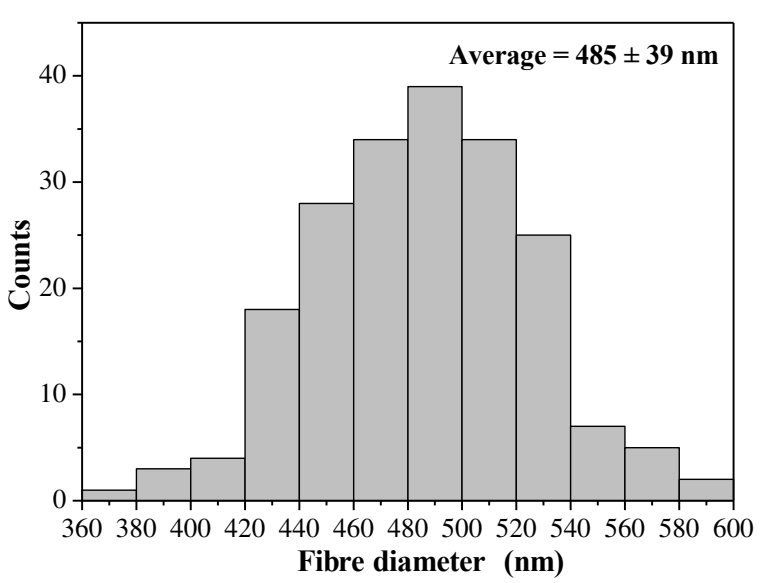

Fig. 4 Size distribution of electrospun fibres with $25 \%$ PSSA-MA.

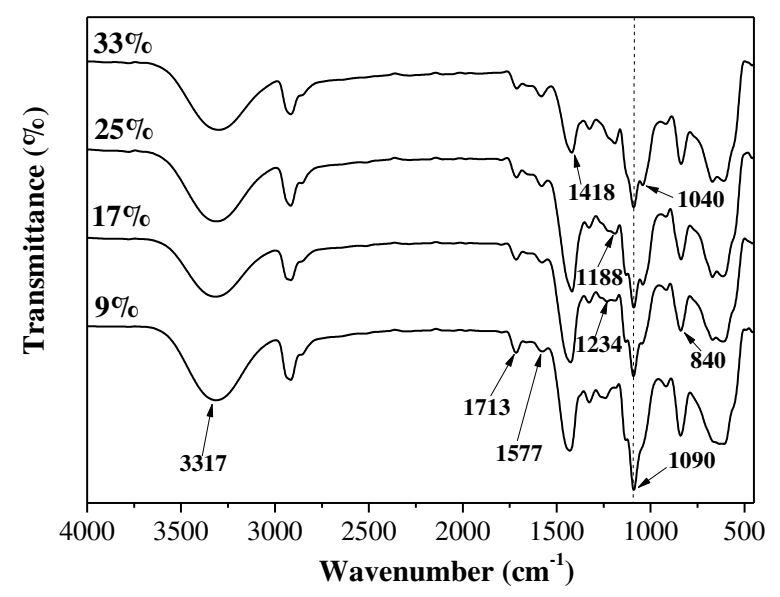

Fig. 5 FTIR spectra of heat-treated electrospun fibres with various PSSA-MA contents.

Fig. 5. The $\mathrm{C}-\mathrm{N}$ stretching band of imidazole ring ${ }^{29}$ was shown at $1577 \mathrm{~cm}^{-1}$. The characteristic bands of PVA at 3317, 1418, and $1090 \mathrm{~cm}^{-1}$ could be designated to $\mathrm{O}-\mathrm{H}$ stretching, $\mathrm{O}-\mathrm{H}$ bending, and $\mathrm{C}-\mathrm{OH}$ stretching, respectively ${ }^{8}$. Weak absorption bands corresponding to $\mathrm{C}=\mathrm{O}$ of ester and $\mathrm{C}-\mathrm{O}-\mathrm{C}$ from polyvinyl acetate residue (5\%) were also observed at 1713 and $1234 \mathrm{~cm}^{-1}$, respectively. Absorption bands corresponding to PSSA-MA at 1188 and $1040 \mathrm{~cm}^{-1}$ were assigned to the $\mathrm{S}=\mathrm{O}$ asymmetric and symmetric stretches, respectively ${ }^{8}$. The wagging vibration of $\mathrm{C}-\mathrm{H}$ in 1,4-substituted benzene ring ${ }^{30}$ of PSSA-MA was shown at $840 \mathrm{~cm}^{-1}$. Although the increment in $\mathrm{C}-\mathrm{O}-\mathrm{C}$ peak intensity at $1234 \mathrm{~cm}^{-1}$ was not clearly observed due to the presence of relatively large amount of $\mathrm{C}-\mathrm{O}-\mathrm{C}$ linkage in pristine PVA, a decrease in $\mathrm{C}-\mathrm{OH}$ peak

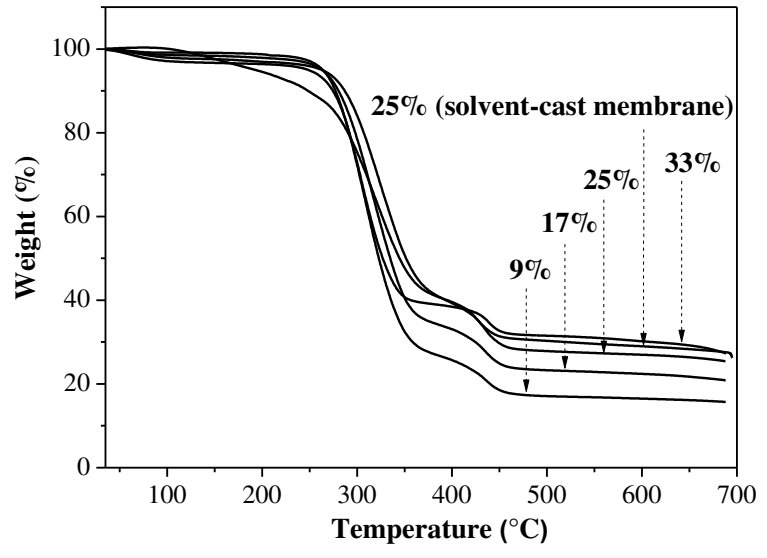

Fig. 6 TGA thermograms of electrospun fibres with 9, 17, 25 , and 33\% PSSA-MA, and of solvent-cast membrane with $25 \%$ PSSA-MA.

intensity at $1090 \mathrm{~cm}^{-1}$ with increasing PSSA-MA concentration implied crosslinking reaction between PVA and PSSA-MA. Degree of crosslinking was found to increase as the wt.\% of PSSA-MA increased. Similar peaks were observed for solvent-cast membrane with 25\% PSSA-MA (data not shown).

\section{Thermal properties}

High thermal stability of membranes is required for good performances at elevated operating temperatures. TGA thermograms of heat-treated fibres were shown in Fig. 6. All samples were thermally stable up to approximately $250^{\circ} \mathrm{C}$, indicating sufficient thermal stability in the temperature range of proton conductivity measurements. Three main degradation stages were observed. The first weight loss below $140^{\circ} \mathrm{C}$ could be attributed to the loss of absorbed water. The second loss between 140 and $380^{\circ} \mathrm{C}$ was related to the losses of sulphonic acid pendants of PSSA-MA and PVA main and side chains. The third loss above $380{ }^{\circ} \mathrm{C}$ corresponded to the loss of PSSA-MA main chain ${ }^{31-33}$. A gradual increase in weight residue with increasing PSSA-MA suggested the increase in degree of crosslinking. Solvent-cast membrane with $25 \%$ PSSA-MA showed similar TGA thermogram to that of fibres.

Glass transition temperatures $\left(T_{\mathrm{g}}\right)$ and melting temperatures $\left(T_{\mathrm{m}}\right)$, obtained from DSC on the second heating cycle, of all fibres and membrane with $25 \%$ PSSA-MA were reported in Table 2. Crystallization temperature $\left(T_{\mathrm{c}}\right)$ on the first cooling cycle was also reported. All samples showed similar $T_{\mathrm{g}}$ values of approximately $81^{\circ} \mathrm{C}$. Slightly lower $T_{\mathrm{m}}$ and $T_{\mathrm{c}}$ values were observed for fibres, indicating the increase in 
Table 2 DSC values of electrospun fibres and solvent-cast membrane with $25 \%$ PSSA-MA.

\begin{tabular}{lcccc}
\hline Sample & $\begin{array}{c}\text { PSSA-MA } \\
(\%)\end{array}$ & $\begin{array}{c}T_{\mathrm{g}} \\
\left({ }^{\circ} \mathrm{C}\right)\end{array}$ & $\begin{array}{c}T_{\mathrm{m}} \\
\left({ }^{\circ} \mathrm{C}\right)\end{array}$ & $\begin{array}{c}T_{\mathrm{c}} \\
\left({ }^{\circ} \mathrm{C}\right)\end{array}$ \\
\hline Electrospun fibres & 9 & 82.2 & 207.8 & 176.1 \\
& 17 & 81.9 & 209.1 & 177.8 \\
& 25 & 81.4 & 207.8 & 171.3 \\
Solvent-cast membrane & 33 & 82.7 & 210.7 & 176.3 \\
\hline
\end{tabular}

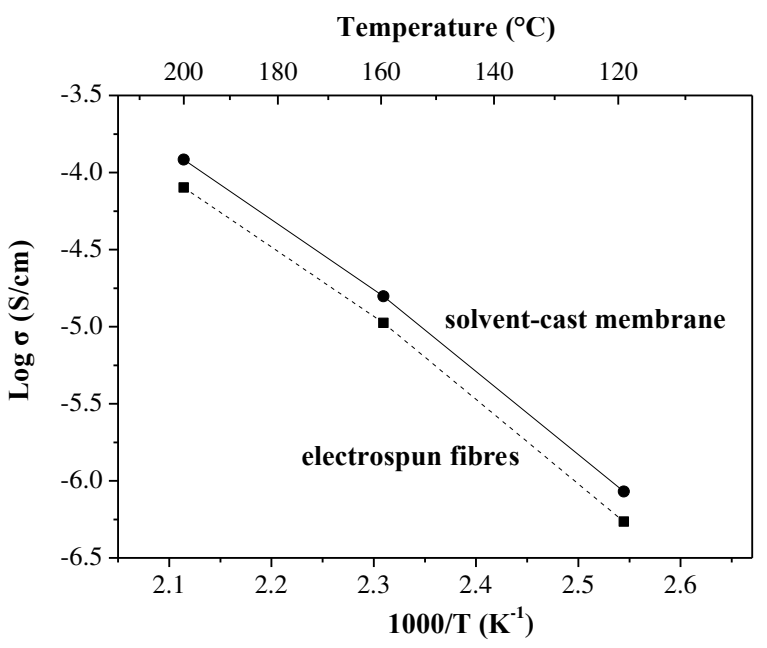

Fig. 7 Proton conductivities of electrospun fibres and solvent-cast membrane with $25 \%$ PSSA-MA.

interruption of the crystallization of PVA.

\section{Proton conductivity}

Proton conductivities of fibres and membrane with $25 \%$ PSSA-MA were determined from $120-200^{\circ} \mathrm{C}$ on cooling down cycle in non-humidified condition. Fig. 7 showed the temperature dependence of proton conductivity as a function of reciprocal temperature. It was found that proton conductivity of solvent-cast membrane was slightly higher than that of fibres. In general, bulk conductivity is predominately governed by segmental mobility and charge carrier density ${ }^{34}$. A small difference in conductivities of fibrous membrane and solvent-cast membrane with similar $T_{\mathrm{g}}$ and identical charge carrier content suggests that there is at least one more factor that influences proton conductivity. Since the measurement of proton conductivity was conducted in the direction of membrane thickness, a denser membrane, that is solvent-cast membrane, might provide a more continuous hydrogen pathway for proton transport. A maximum conductivity of $121 \mu \mathrm{S} / \mathrm{cm}$ was achieved from solvent-cast membrane at $200^{\circ} \mathrm{C}$.

\section{CONCLUSIONS}

Proton conducting membranes based on crosslinked PVA, PSSA-MA, and imidazole for use at elevated temperatures were successfully prepared via electrospinning and solvent-cast methods. Fibre mats were obtained from most compositions; however, uniform fibres were only produced from solution with $25 \%$ PSSA-MA. Fibre diameter was found to increase with increasing solution viscosity. All membranes were thermally stable up to $250^{\circ} \mathrm{C}$ under nitrogen atmosphere. The increase in PSSA-MA content resulted in an enhancement in thermal stability probably due to higher degree of crosslinking. Proton conductivity increased with increasing temperature. Besides mobility and charge carrier density in polymeric membranes, membrane density would likely be accounted for the small increment in conductivity of the solvent-cast membrane.

Acknowledgements: Funding was provided by Higher Education Research Promotion and National Research University Project of Thailand, Office of the Higher Education Commission, through the Advanced Functional Materials Cluster of Khon Kaen University, the Nanotechnology Centre (NANOTEC), NSTDA, Ministry of Science and Technology, Thailand, through its program of Centre of Excellence Network, and the Centre for Innovation in Chemistry (PERCH-CIC), Commission on Higher Education, Ministry of Education. The authors gratefully acknowledge the National Metals and Materials Technology Centre (MTEC) for conductivity measurement.

\section{REFERENCES}

1. Whittingham MS, Savinell RF, Zawodzinski T (2004) Introduction: Batteries and fuel cells. Chem Rev 104, 4243-4.

2. Steele BCH, Heinzel A (2001) Materials for fuel-cell technologies. Nature 414, 345-52.

3. Hickner MA, Ghassemi H, Kim YS, Einsla BR, McGrath JE (2004) Alternative polymer systems for proton exchange membranes (PEMs). Chem Rev 104, 4587-611.

4. Küver A, Vielstich W (1998) Investigation of methanol crossover and single electrode performance during PEMDMFC operation: A study using a solid polymer electrolyte membrane fuel cell system. J Power Sourc 74, 211-8.

5. Smitha B, Sridhar S, Khan AA (2006) Chitosanpoly(vinyl pyrrolidone) blends as membranes for direct methanol fuel cell applications. J Power Sourc 159, 846-54.

6. Rhim JW, Yeom CK, Kim SW (1998) Modification of poly(vinyl alcohol) membranes using sulfur-succinic acid and its application to pervaporation separation 
of water-alcohol mixtures. J Appl Polymer Sci 68, 1717-23.

7. Chiang WY, Chen CL (1998) Separation of wateralcohol mixture by using polymer membranes6. Water-alcohol pervaporation through terpolymer of PVA grafted with hydrazine reacted SMA. Polymer 39, 2227-33.

8. Zhu M, He B, Shi W, Feng Y, Ding J, Li J, Zeng F (2010) Preparation and characterization of PSSA/PVA catalytic membrane for biodiesel production. Fuel 89, 2299-304.

9. Gribov EN, Parkhomchuk EV, Krivobokov IM, Darr JA, Okunev AG (2007) Supercritical $\mathrm{CO}_{2}$ assisted synthesis of highly selective nafion-zeolite nanocomposite membranes for direct methanol fuel cells. J Membr Sci 297, 1-4.

10. Silva VS, Ruffmann B, Silva H, Silva VB, Mendes A, Madeira LM, Nunes S (2006) Zirconium oxide hybrid membranes for direct methanol fuel cells-Evaluation of transport properties. J Membr Sci 284, 137-44.

11. Rikukawa M, Sanui K (2000) Proton-conducting polymer electrolyte membranes based on hydrocarbon polymers. Progr Polymer Sci 25, 1463-502.

12. Smitha B, Sridhar S, Khan AA (2005) Solid polymer electrolyte membranes for fuel cell applications-a review. J Membr Sci 259, 10-26.

13. Zhang JL, Xie Z, Zhang JJ, Tanga YH, Song CJ, Navessin T, Shi ZQ, Song DT, Wang HJ, Wilkinson DP, Liu ZS, Holdcroft S (2006) High temperature PEM fuel cells. J Power Sourc 160, 872-91.

14. Shao YY, Yin GP, Wang ZB, Gao YZ (2007) Proton exchange membrane fuel cell from low temperature to high temperature: Material challenges. J Power Sourc 167, 235-42.

15. Li QF, He RH, Jensen JO, Bjerrum NJ (2003) Approaches and recent development of polymer electrolyte membranes for fuel cells operating above $100^{\circ}$ C. Chem Mater 15, 4896-915.

16. Kreuer KD, Paddison SJ, Spohr E, Schuster M (2004) Transport in proton conductors for fuel-cell applications: Simulations, elementary reactions, and phenomenology. Chem Rev 104, 4637-78.

17. Münch W, Kreuer KD, Silvestri W, Maier J, Seifert G (2001) The diffusion mechanism of an excess proton in imidazole molecule chains: first results of an ab initio molecular dynamics study. Solid State Ionics 145, 437-43.

18. Schuster MFH, Meyer WH (2003) Anhydrous protonconducting polymers. Annu Rev Mater Res 33, 233-61.

19. Borup R, Meyers J, Pivovar B, Kim YS, Mukundan R, Garland N, Myers D, Wilson M, et al (2007) Scientific aspects of polymer electrolyte fuel cell durability and degradation. Chem Rev 107, 3904-51.

20. Tamura T, Kawakami H (2010) Aligned electrospun nanofiber composite membranes for fuel cell electrolytes. Nano Lett 10, 1324-8.

21. Chen H, Snyder JD, Elabd YA (2008) Electrospinning and solution properties of nafion and poly(acrylic acid). Macromolecules 41, 128-35.

22. Bajon R, Balaji S, Guo SM (2009) Electrospun nafion nanofiber for proton exchange membrane fuel cell application. J Fuel Cell Sci Tech 6, 0310041-6.

23. Martwiset S, Jaroensuk K (2012) Electrospinning of poly(vinyl alcohol) and poly(4-styrenesulfonic acid) for fuel cell applications. J Appl Polymer Sci 124, 2594-600.

24. Kim DS, Park HB, Rhim JW, Lee YM (2005) Proton conductivity and methanol transport behavior of crosslinked PVA/PAA/silica hybrid membranes. Solid State Ionics 176, 117-26.

25. Huang ZM, Zhang YZ, Kotaki M, Ramakrishna S (2003) A review on polymer nanofibers by electrospinning and their applications in nanocomposites. Compos Sci Tech 63, 2223-53.

26. Greiner A, Wendorff JH (2007) Electrospinning: A fascinating method for the preparation of ultrathin fibers. Angew Chem Int Ed 46, 5670-703.

27. Schiffman JD, Schauer CL (2008) A review: Electrospinning of biopolymer nanofibers and their applications. Polymer Rev 48, 317-52.

28. Zhong Z, Cao Q, Wang XY, Wu N, Wang Y (2012) PVC-PMMA composite electrospun membranes as polymer electrolytes for polymer lithium-ion batteries. Ionics 18, 47-53.

29. Boroglu MS, Celik SU, Bozkurt A, Boz I (2011) The synthesis and characterization of anhydrous proton conducting membranes based on sulfonated poly(vinyl alcohol) and imidazol. J Membr Sci 375, 157-64.

30. Bekri-Abbes I, Bayoudh S, Baklouti M (2006) Converting waste polystyrene into adsorbent: Potential use in the removal of lead and cadmium ions from aqueous solution. J Polymer Environ 14, 249-56.

31. Martwiset S, Woudenberg RC, Granados-Focil S, Yavuzcetin O, Tuominen MT, Coughlin EB (2007) Intrinsically conducting polymers and copolymers containing triazole moieties. Solid State Ionics 178, 1398-403.

32. Cho CG, Jang HY, You YG, Li GH, An SG (2006) Preparation of poly(phenylene oxide-g-styrenesulfonic acid) and their characterization for DMFC membrane. High Perform Polymer 18, 579-91.

33. Holland BJ, Hay JN (2001) The thermal degradation of poly(vinyl alcohol). Polymer 42, 6775-83.

34. Persson JC, Jannasch P (2003) Self-conducting benzimidazole oligomers for proton transport. Chem Mater 15, 3044-5. 